\title{
O USO DE IMAGENS SENTINEL-2 E DO SOFTWARE LIVRE QGIS NO ZONEAMENTO AMBIENTAL: UM ESTUDO DE CASO NO MUNICÍPIO DE SÃO BENTO, PARAÍBA, NORDESTE DO BRASIL
}

\author{
George Pereira de Oliveira ${ }^{(a)}$, Bruno de Azevedo Cavalcanti Tavares ${ }^{(b)}$, Francisco Clésio \\ Medeiros Dantas de Araújo ${ }^{(c)}$
}

\author{
(a) Programa de Pós-graduação em Geografia, Universidade Federal de Pernambuco, georgesb@ bol.com.br \\ (b) Departamento de Arqueologia/Centro de Filosofia e Ciências Humanas, Universidade Federal de Pernambuco, \\ brunoactavares@gmail.com \\ (c) Programa de Pós-graduação em Geografia - Mestrado Profissional, Centro de Ensino Superior do Seridó, \\ Universidade Federal do Rio Grande do Norte, prof.clesiogeo@gmail.com
}

\section{Eixo: GEOTECNOLOGIAS E MODELAGEM ESPACIAL EM GEOGRAFIA FÍSICA}

\begin{abstract}
Resumo
Desde a promulgação da Política Nacional do Meio Ambiente em 1981, o zoneamento ambiental vem adqurindo uma considerável visibilidade. As metodologias de zoneamento mais utilizadas muitas vezes são fundamentadas com base em metodologias complexas e softwares de alto custo. Novas metodologias surgem para simplificar o processo de elaboração, assim como a de Costa, Guedes e Rocha (2014). Este estudo objetiva elaborar um roteiro de zoneamento ambiental, fundamentado na referida metodologia mediante a utilização de geotecnologias livres. O recorte espacial escolhido foi o município de São Bento - PB. Para atingir o objetivo proposto utilizaram-se imagens de satélite Sentinel-2 e o software livre QGIS. Foram delimitadas três zonas distintas: zonas de uso restrito, zonas de risco e zonas de recuperação. O zoneamento ambiental alcançado manteve o rigor técnicocientífico, imprescindível ao desenvolvimento de políticas públicas de planejamento e gestão ambiental, e apresenta uma linguagem visual de fácil apreensão pelo público leigo.
\end{abstract}

Palavras chave: Zonas ambientais; uso e cobertura da terra; geotecnologias livres.

\section{Introdução}

Desde a promulgação da Política Nacional do Meio Ambiente (BRASIL, 1981), o zoneamento ambiental passou a compor as políticas públicas de gestão e planejamento territorial. No meio acadêmico brasileiro, é comum a associação entre zoneamento ambiental e unidades de paisagem (Geossistemas), destacando-se os estudos de Souza (2000), Diniz e Vasconcelos (2010), Amorim e Oliveira (2013), dentre outros (GILIOTTI; OLIVEIRA, 2015; DIAS; BACC; OLIVEIRA, 2015; DINIZ; OLIVEIRA; 2015).

Para que o zoneamento ambiental seja implementado de forma eficiente, ele deve ter a capacidade de ser representado de forma concisa, de modo que ele possa ser assimilado pelas partes interessadas em sua aplicação. Portanto, é necessária a tradução da complexa interação dos sistemas ambientais através de metodologias que, mantendo o rigor científico imprescindível, são mais simplificadas. Dentre essas, 
destaca-se a estratégia de zoneamento elaborada por Costa, Guedes e Rocha (2014), que delimita as diferentes zonas geoecológicas de acordo com o seu grau de degradação expresso pela densidade ou ausência da vegetação. Os seus procedimentos foram desenvolvidos tendo como base sistemas de ambientes semiáridos. Inicialmente, aplicada pelos referidos autores em margens de reservatórios, a mesma se mostrou eficaz para o zoneamento ambiental em escala microrregional e municipal (ARAGÃO et al., 2014), além da gestão de microbacias hidrográficas (GUEDES; MEDEIROS; COSTA, 2016).

Apesar de ser relativamente simples e dar respostas de forma rápida, o que a torna consideravelmente útil para os agentes incumbidos de elaborar o zoneamento ambiental, os trabalhos citados anteriormente que fazem uso da referida metodologia (COSTA, GUEDES, ROCHA, 2014; ARAGÃO et al., 2014; GUEDES; MEDEIROS; COSTA, 2016) utilizam roteiros de mapeamento que envolvem softwares de geoprocessamento privativos.

Nesta perspectiva, este estudo teve como objetivo elaborar um zoneamento ambiental fundamentado na metodologia de Costa, Guedes e Rocha (2014) por meio de geotecnologias livres. Para isso, foram utilizadas imagens do satélite Sentinel-2 e o software livre QGIS, escolhendo-se o município de São Bento - PB como recorte espacial para o exercício prático e testes dos procedimentos.

\section{Materiais e Métodos}

\section{1 Área de Estudo}

O município de São Bento está localizado no Alto Sertão da Paraíba, a $450 \mathrm{~km}$ da capital João Pessoa (Figura 1). O município possui uma população total estimada em 2016 de 33.847 habitantes distribuídos por uma área de $248,2 \mathrm{~km}^{2}$ (IBGE, 2016).

A geologia da área de estudo é caracterizada pela predominância de litotipos cristalinos, principalmente metagranitos da suíte intrusiva Poço da Cruz e ortognaisses do Complexo Caicó, além de dioritos e granodioritos do plúton Catolé do Rocha e granitoides indiscriminados (SANTOS; FERREIRA; SILVA JR, 2002). As únicas áreas sedimentares são os depósitos aluvionares quaternários da planície fluvial do rio Piancó-Piranhas-Açu, que possuem maior potencialidade para o acúmulo de águas subterrâneas (SANTOS; FERREIRA; SILVA JR, 2002). 


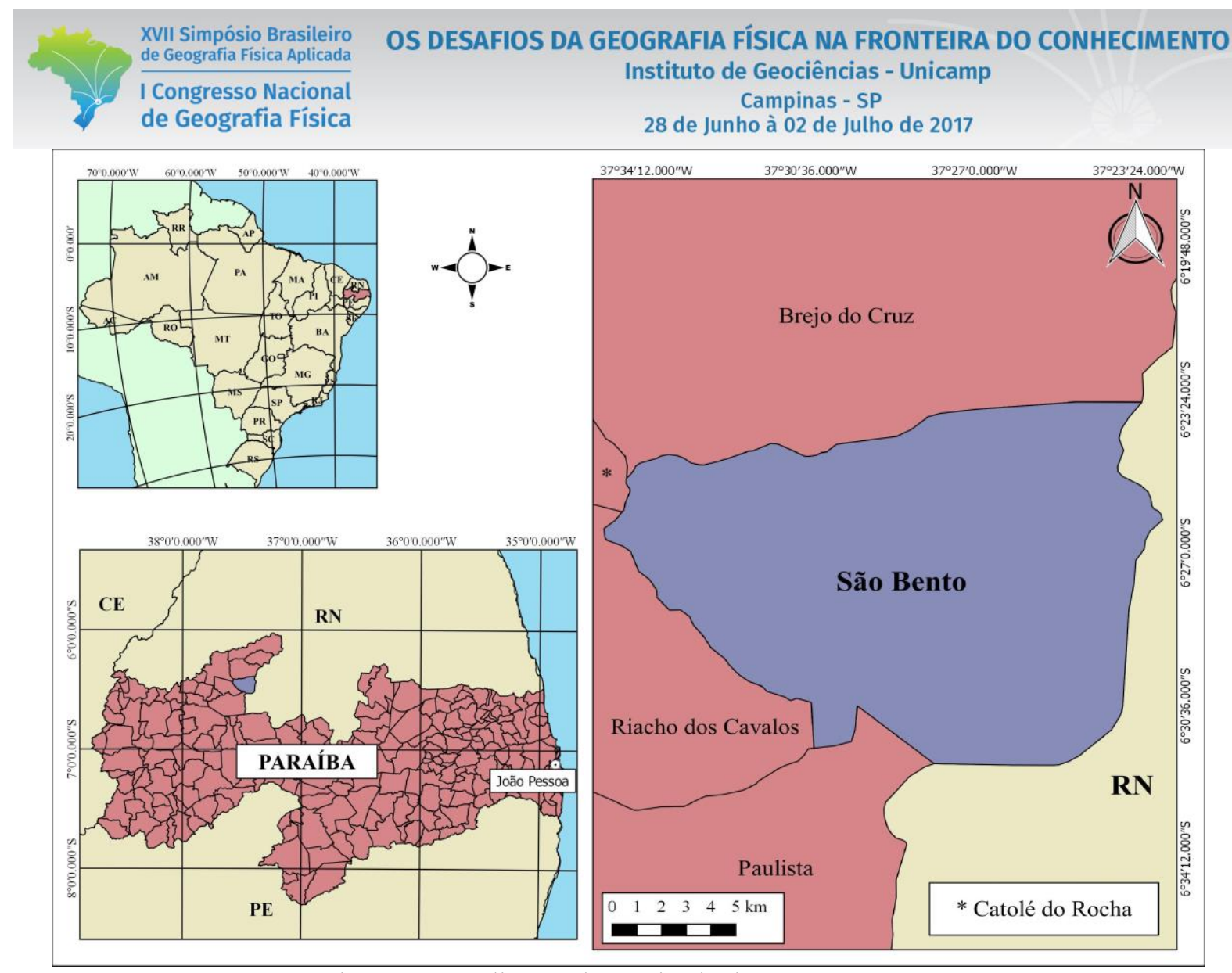

Figura 1 - Localização do município de São Bento - PB.

A área compreende a bacia hidrográfica do Piancó-Piranhas-Açu, cujo curso do canal principal, denomiminado na região de Piranhas-Açu, atravessa o munícipio de São Bento - PB de uma extremidade à outra em sentido NE-SW (AESA, 2008). Praticamente todas as áreas urbanizadas e principais atividades econômicas se desenvolvem no entorno desse rio, sendo sua planície de inundação e adjacências uma das áreas que mais sofrem com os efeitos da antropização (ARAÚJO, 2011). Inexistem no município grandes açudes, sendo os de pequeno porte construídos em propriedades rurais para dar suporte á irrigação dos campos de cultivo (AESA, 2008).

De acordo com Nimer (1977), o clima da região é o Tropical de Zona Equatorial, subtipo semiárido mediano com 7 a 8 meses secos. Como indicado por Molion e Bernardo (2002), o principal gerador de precipitações nesta porção do Nordeste é a Zona de Convergência Intertropical (ZCIT), sendo a sua máxima atuação nos meses de março a abril. Nestes meses verificam-se os maiores totais pluviométricos, com valores médios de $800 \mathrm{~mm} /$ ano (SUDENE, 1990). A temperatura média anual é de aproximadamente $26^{\circ} \mathrm{C}$, com variações que vão de 21 a $33{ }^{\circ} \mathrm{C}$ (SUDENE, 1990). Os ventos predominantes são de SE.

A paisagem é caracterizada pelas depressões semiáridas florestadas por caatingas arbustivas, cuja configuração do relevo varia de ondulada a suavemente ondulada (OLIVEIRA; DINIZ, 2015). A planície 
fluvial do Piancó-Piranhas-Açu se apresenta como uma área de relevo plano (AESA, 2008). À NW do município se situam as maiores altitudes e declividades, mais especificamente onde aflora o plúton Catolé do Rocha, tratando-se este trecho de um campo de inselbergs que possui continuidade em municípios circunvizinhos (OLIVEIRA; DINIZ, 2015).

A pedologia do município é marcada pela ocorrência de diversas manchas de luvissolos crômicos (EMBRAPA, 1974; 2014), áreas bastante aproveitadas para a agropecuária em virtude de sua média fertilidade. Neossolos flúvicos ocorrem na planície de inundação do rio Piancó-Piranhas-Açu, enquanto neossolos litólicos também são frequentemente encontrados, principalmente nos trechos de afloramento do plúton Catolé do Rocha (EMBRAPA, 1974).

\subsection{Procedimentos Metodológicos}

A elaboração deste estudo seguiu as seguintes etapas principais, com base em Costa, Guedes e Rocha (2014): 1) revisão bibliográfica e cartográfica sobre metodologias de zoneamento ambiental e informações físico-naturais sobre a área de estudo; 2) aquisição dos produtos de sensoriamento remoto; 3) produção do mapa de classes de uso e ocupação do solo no software QGIS com base em um roteiro devidamente testado; e 4) elaboração do zoneamento ambiental com base nas classes de uso e ocupação do solo.

As imagens de satélite foram adquiridas gratuitamente no site de distribuição de produtos de sensoriamento da NASA (National Aeronautics and Space Administration), o EarthExplorer. Foram utilizadas imagens da missão Sentinel-2 da ESA (European Space Agency). Essa missão tem por objetivo produzir imagens de média resolução para fins de planejamento, possuindo bandas espectrais de 10, $20 \mathrm{e}$ 60 m de resolução espacial que cobrem um campo de visão de $290 \mathrm{~km}$, sendo sua resolução temporal de 5 dias (contando para isso com dois satélites) (MEER; WERFF; RUITENBEEK, 2014).

Neste estudo, foram utilizadas as bandas Sentinel-2 do sensor MSI (multi-spectral instrument) de resolução espacial de 10 m (órbita 52), composições falsa cor R8G4B3 e R4G8B3 (Figura 2), obtidas em 11/02/2016. As bandas 3 e 4 situam-se no espectro visível, correspondendo às cores verde e vermelho, respectivamente. A banda 8 corresponde ao espectro infravermelho próximo. Buscou-se com isso realçar as características da vegetação, principalmente o seu grau de densidade. 

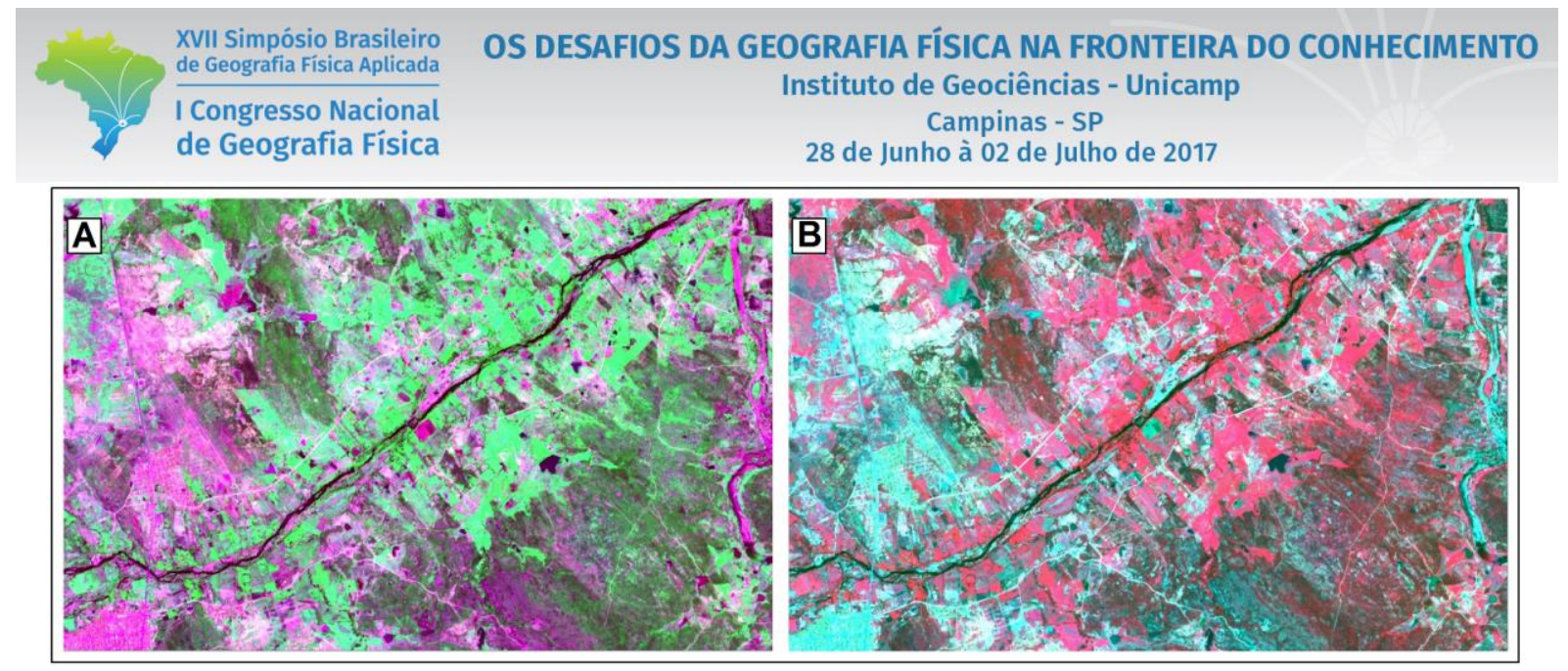

Figura 2 - Composições de bandas falsa cor elaboradas com base nas bandas Sentinel-2 do sensor MSI (multispectral instrument) de resolução espacial de 10 m (órbita 52) obtidas em 11/02/2016. A - Composição R4G8B3; B Composição R8G4B3.

Os procedimentos de pré-processamento, composição e classificação de imagens foi feito no software QGIS 2.14.11 Essen (versão de longa duração), através do complemento SCP (Semi-Automatic Classificatio Plugin) versão 5.0, desenvolvido por Congedo (2013). Este complemento possui um conjunto de ferramentas desenvolvido exclusivamente para as especificidades das imagens Sentinel-2.

As bandas espectrais, baixadas com o datum WGS 1984, foram reprojetadas para o datum SIRGAS 2000. Trabalhou-se com o sistema de coordenadas geográficas (EPSG 4674). As mesmas também passaram por correção geométrica. Após a ativação do plugin SCP no gerenciador de complementos do QGIS, as bandas foram importadas para o software e, na etapa de pré-processamento foram, submetidas à técnica de correção atmosférica Dark Object Subtraction 1 (DOS1). Com isso procedeu-se para a etapa de composição de bandas.

O mapa de classes de uso e cobertura da terra foi elaborado a partir de classificação semi-automática de imagens, com base no métoda da Máxima Verossimilhança - MaxVer. Neste os pixels são relacionados a uma determinada classe por probabilidade estatística, a partir de polígonos amostrais (SWAIN; DAVIS, 1978). A definição das classes fundamentou-se no Manual Técnico de Uso da Terra (IBGE, 2013). A escala de trabalho utilizada foi de 1:50.000. Foram distinguidas as seguintes classes: área urbanizada, corpos hídricos, caatinga densa, caatinga rala, agricultura e solo exposto

A metodologia de zoneamento ambiental empregada foi a de Costa, Guedes e Rocha (2014), que tem como base a dinâmica geoecológica de ambientes semiáridos. Com base nessa metodologia, foi analisado o grau de degradação da qualidade ambiental das diferentes zonas ao longo do território do município estudado, sendo a vegetação o principal indicador destacado. Entendeu-se como degradação da qualidade ambiental as alterações adversas das características naturais do meio ambiente, confome a Política 
Nacional do Meio Ambiente (BRASIL, 1981). A área foi classificada em três zonas distintas: zonas de uso restrito, zonas de risco e zonas de recuperação. Além disso, indicou-se o grau de necessidade de intervenção de cada uma das respectivas zonas, sendo este o indicador que direciona o nível de urgência das ações a serem implantadas (ARAGÃO et al., 2014). Foram identificados três níveis de prioridade: alta, elevada e extrema.

De acordo com Aragão et al. (2014), é importante lembrar que esta abordagem de zoneamento se limita à cenarios rurais, considerando que para as áreas urbanizadas já existem uma legislação abrangente destinada a dar suporte à gestão pública.

4. Resultados e discussãoPor ser um município de economia fortemente dependente da indústria têxtil, atividade que implica em fortes pressões sobre o meio ambiente, o zoneamento ambiental municipal em São Bento - PB se apresenta em um caráter fundamental para o desenvolvimento sustentável local. Araújo (2011) elencou os impactos desta atividade no referido município, sendo esses: o desmatamento da vegetação arbórea nativa para a produção de lenha, principal fonte de energia dos fornos nas fábricas; poluição atmosférica devido às chaminés das indústrias; poluição das águas fluviais devido à má destinação dos resíduos líquidos industriais; e o descarte inadequado dos resíduos sólidos. Contudo, a maioria destes impactos, excetuando-se a poluição fluvial que causa efeitos negativos em diversos municípios a jusante de seu curso, estão concentrados na área urbanizada.

A classificação supervisionada das imagens Sentinel-2 permitiu a confecção de um mapa de classes de uso e cobertura da terra (Figura 3). As informações referentes à área de cada uma dessas classes e a proporção em porcentagem em relação ao tamanho do município podem ser consultadas na tabela I. 


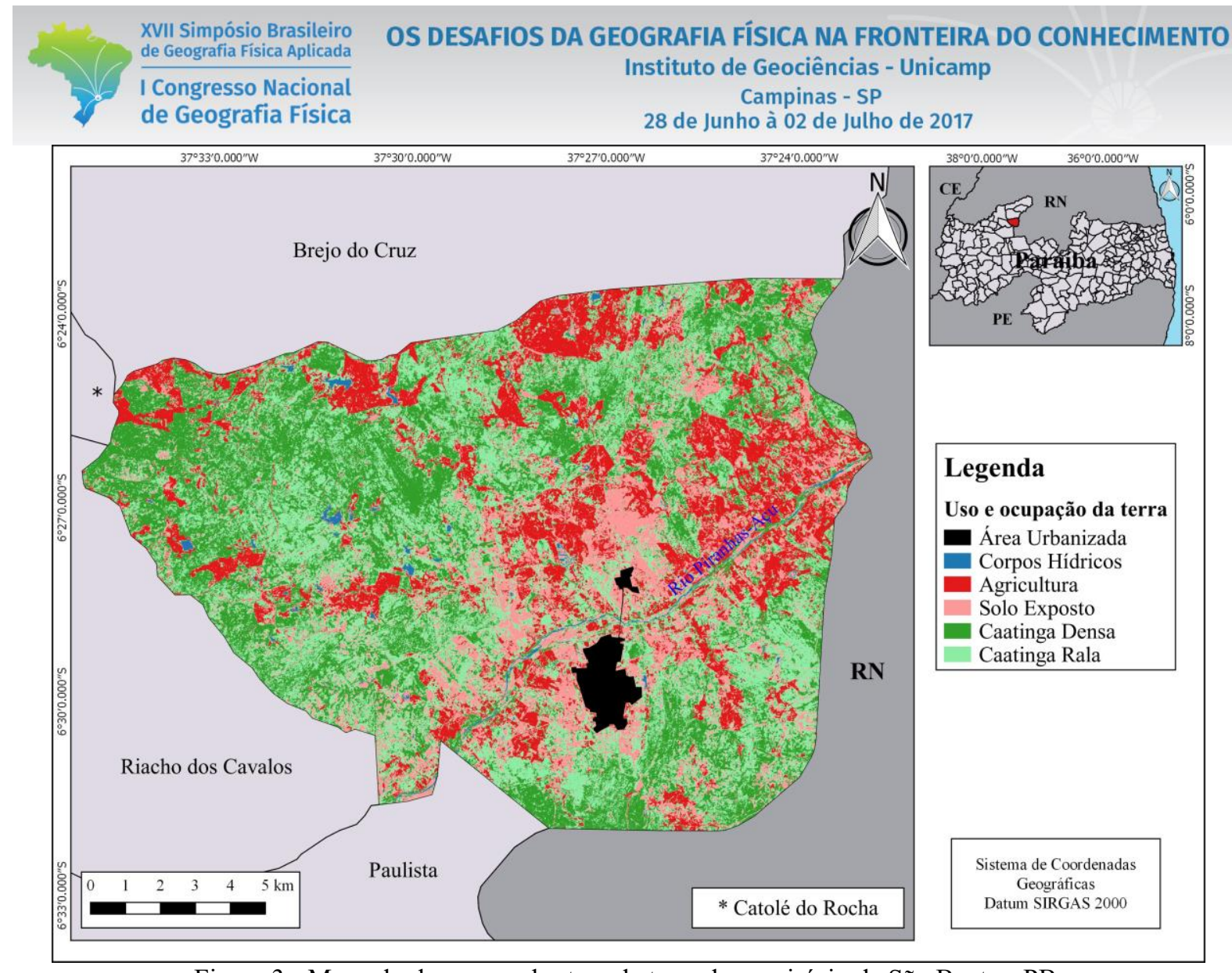

Figura 3 - Mapa do de uso e cobertura da terra do município de São Bento - PB.

Tabela I - Área $\left(\mathrm{em} \mathrm{km}^{2} \mathrm{e} \%\right)$ das classes uso e cobertura da terra no município de São Bento - PB.

\begin{tabular}{c|c|c}
\hline $\begin{array}{c}\text { Classes de uso e cobertura } \\
\text { da terra }\end{array}$ & Área $\left(\mathbf{K m}^{\mathbf{2}}\right)$ & $\begin{array}{c}\text { \% em relação ao tamanho } \\
\text { do município }\end{array}$ \\
\hline Área Urbanizada & 4 & $1,8 \%$ \\
Corpos Hídricos & 2 & $0,8 \%$ \\
Caatinga Densa & 73 & $29,4 \%$ \\
Caatinga Rala & 84 & $33,8 \%$ \\
Agricultura & 51 & $20,5 \%$ \\
Solo Exposto & 34 & $13,7 \%$ \\
\hline
\end{tabular}

Os corpos hídricos dizem respeito aos pequenos açudes, a maioria construídos pela iniciativa privada para dar suporte à irrigação das áreas de cultivo e de criação de gado, e ao rio Piranhas-Açu propriamente dito. Em virtude de situarem-se ao redor destes açudes a maioria das propriedades onde se desenvolvem as atividades agropecuárias do município, estas áreas estão sujeitas a fortes pressões ambientais. 
As áreas remanescentes de vegetação nativa ou em recuperação (Figura 3), aumentam conforme o maior distanciamento das margens do Piranhas-Açu, o que comprova o maior estágio de degradação ambiental próximo ao seu curso. Isso se deve ao fato de que, por questões de disponibilidade de água, a planície de inundação do referido canal é utilizada para o desenvolvimento das atividades agropecuárias existentes e, consequentemente, está sujeita ao processo de desmatamento.A caatinga densa, que compreende os trechos de vegetação nativa com porte arbustivo-arbóreo mais conservado e de maior diversidade de espécies, está localizada nos trechos de maior altitude $(400$ a $450 \mathrm{~m})$ e declividade $\left(45^{\circ}\right.$ a $70^{\circ}$ de inclinação) do território municipal. As dificuldades de ocupação impostas pelo relevo íngreme mantêm essas áreas pouco antropizadas. Os segmentos de caatinga rala, por sua vez, tratam-se de áreas que foram mais exploradas no passado, sobretudo no ciclo da cotonicultura da segunda métade do século passado, e agora encontram-se em recuperação devido à diminuição do seu ritmo de degradação (DINIZ; OLIVEIRA, 2015). A sua diversidade de espécies é menor, predominando na paisagem espécimes de Jurema-preta (Mimosa tenuiflora [Willd.] Poiret).

As atividades agropecuárias estão concentradas na planície de inundação do rio Piranhas-Açu e adjacências, como já dito anteriormente, e ao redor de pequenos açudes que pontilham a zona rural do município de forma dispersa. Dentre os principais gêneros agrícolas cultivados estão o feijão e o milho e, ainda, a banana (IBGE, 2015).

As áreas de solo exposto geralmente são trechos desmatados para servir de pasto para o gado ou para dar lugar aos campos de cultivos. Em virtude dos longos períodos de estiagem naturais da região, os planos de cultivo são abortados e as áreas permanecem por muito tempo sem nenhuma forma de cobertura vegetal. O uso de técnicas de manejo inadequadas também contribui para a expansão dessas áreas, pois retira a fertilidade natural do solo e o torna inapropriado.

Essas diferentes classes de uso e cobertura da terra foram analisadas para a produção do mapa de zoneamento ambiental do município de São Bento - PB. Com base na metodologia de Costa, Guedes e Rocha (2014), foram distinguidas três zonas: zonas de uso restrito, zonas de risco e zonas de recuperação (Figura 4 e Tabela II). 


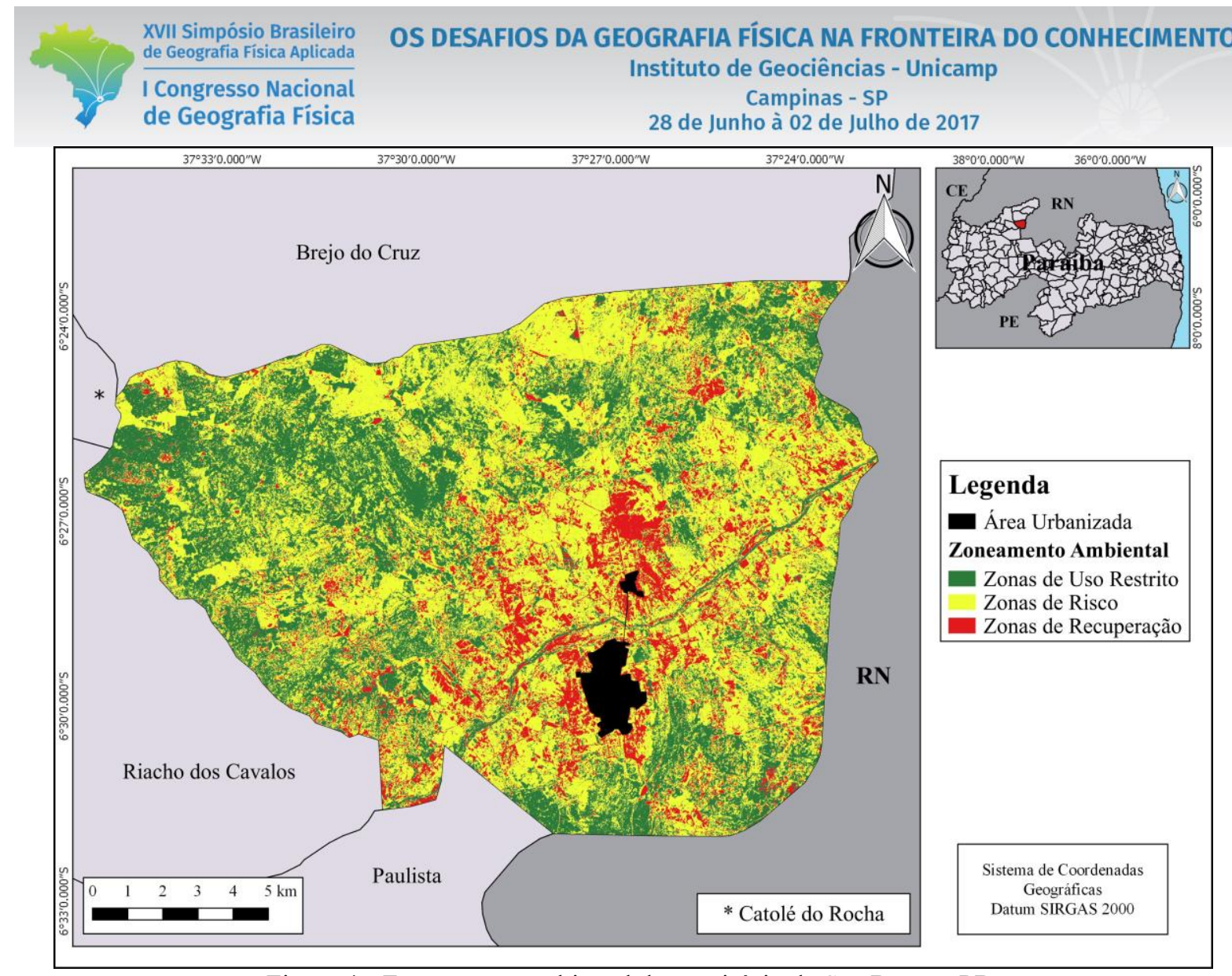

Figura 4 - Zoneamento ambiental do município de São Bento - PB.

Tabela II - Categorias de zoneamento e prioridade de intervenção.

\begin{tabular}{c|c|c|c|c}
\hline $\begin{array}{c}\text { Categorias do } \\
\text { Zoneamento }\end{array}$ & $\begin{array}{c}\text { Classes de uso } \\
\text { do solo } \\
\text { correspondente }\end{array}$ & Prioridade & Área $\left.\mathbf{( K m}^{\mathbf{2}}\right)$ & $\begin{array}{c}\text { \% em relação ao } \\
\text { tamanho do } \\
\text { município }\end{array}$ \\
\hline Zona de Uso Restrito & $\begin{array}{c}\text { Caatinga densa } \\
\text { e corpos } \\
\text { hídricos }\end{array}$ & Alta & 75 & $30,2 \%$ \\
Zona de Risco & $\begin{array}{c}\text { Caatinga rala e } \\
\text { Agricultura } \\
\text { Zolo exposto }\end{array}$ & Elevada & 135 & $54,3 \%$ \\
\hline
\end{tabular}

As zonas de uso restrito (Figura 5-A) compreendem os corpos hídricos e os remanescentes de caatinga densa. Estas zonas são as que possuem um estágio menos avançado de degradação ambiental. Como afirma Costa, Guedes e Rocha (2014), são áreas mais apropriadas para o desenvolvimento de atividades recreativas e educacionais. Possuem alta prioridade de intervenção. No contexto do município de São 
XVII Simpósio Brasileiro

de Geografia Física Aplicada

I Congresso Nacional

de Geografia Física
OS DESAFIOS DA GEOGRAFIA FÍSICA NA FRONTEIRA DO CONHECIMENTO

Instituto de Geociências - Unicamp

Campinas - SP

28 de Junho à 02 de Julho de 2017

Bento - PB, o turismo ecológico ou até mesmo de aventura, nas áreas mais elevadas e declivosas, onde a vegetaçao densa está preservada, tem potencial para gerar renda à população local.

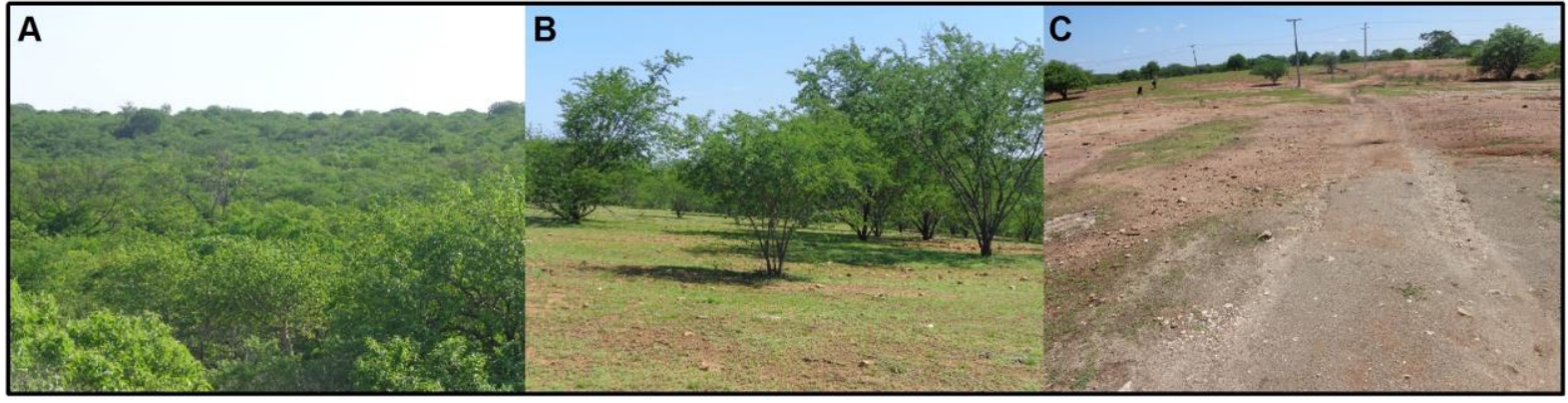

Figura 5 - Fotografias ilustrativas da composição das zonas ambientais identificadas em São Bento - PB. A - Zona de uso restrito (Caatinga densa); B - Zona de risco (Caatinga rala); C - Zona de recuperação (solo exposto). Fonte:

Acervo dos autores.

Os trechos de caatinga rala e de agricultura correspondem às zonas de risco (Figura 5-B), caracterizadas pela intensa degradação ambiental e ocupação irregular, que promoveram uma retirada parcial da vegetação e, consequentemente, aumentaram à susceptibilidade erosiva do solo (ARAGÃO et al., 2014). A maior percela do município se insere nessas zonas (54,3\%). A prioridade de intervenção nessa zona é elevada. As técnicas de manejo nessas zonas, principalmente nas áreas agrícolas, devem ser revistas. É importante que seja oferecida assistência técnica para os produtores visando o aumento de sua produtividade e redução dos impactos provocados por métodos de preparação da terra arcaicos, como a queima do solo, além de técnicas mais recentes, como o uso intensivo de agrotóxicos.

As zonas de recuperação (Figura 5-C) são compostas pelos trechos de solo exposto, e apresentam uma prioridade extrema de intervenção. São áreas bastante suscetíveis à erosão dos solos devido à ausência de vegetação. Portanto, é urgente o desenvolvimento de iniciativas que promovam a recuperação de seu equilíbrio geoecológico, como o replantio de espécies de vegetação nativa e o não desenvolvimento de novas atividas por um período necessário para a sua recuperação.

\section{Considerações finais}

A metodologia de zoneamento de Costa, Guedes e Rocha (2014), a qual foi adotada neste estudo, apresentou uma aplicabilidade prática e simples, portanto, muito útil quando se necessitam de resultados rápidos para guiar o desenvolvimento de políticas de planejamento e gestão ambiental municipal. O uso do QGIS e de imagens Sentinel-2 não acarretou em nenhuma perda de rigor técnico-científico. Com isso, admite-se que as geotecnologias livres podem ser uma importante ferramenta de suporte para os agentes planejadores e gestores púbicos. 


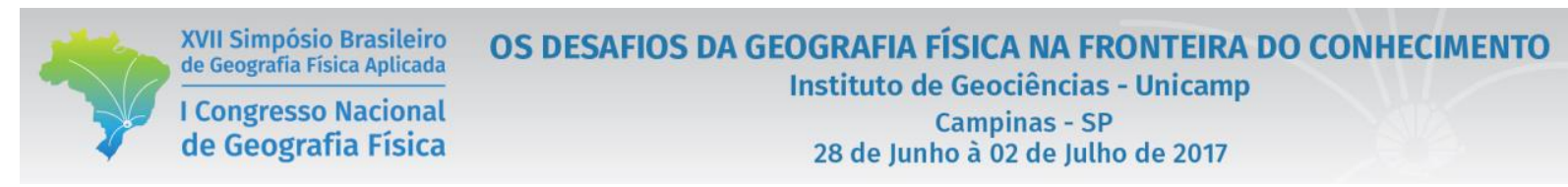

Com relação ao município de São Bento - PB, esse foi caracterizado por áreas em estágio de degradação ambiental. O relevo acidentado protege as principais áreas de remanescentes de vegetação que não foram tão antropizadas, enquadrando-se nas zonas de uso restrito. As zonas de risco (caatinga rala e agricultura), por não terem atingido um grau extremo de degradação, merecem uma atenção especial para que se possa evitar a perda de seu equílibrio geoecológico. Para as zonas de recuperação (solo exposto), é necessário adotar medidas de regeneração da vegetação nativa, como replantio e descanso das terras, para que essas possam readquirir a sua qualidade ambiental.

O mapa de zoneamento ambiental é estruturado de forma simples, favorecendo a sua leitura por leigos. Ao invés de mostrar um emaranhado de polígonos e nomenclaturas complexas, ele mostra somente três zonas distintas que, pelo seu padrão de cores (verde, amarelo, vermelho), consegue passar rapidamente uma ideia de progressão dos níveis de degradação. Isso o torna bastante útil para políticas ambientais que objetivam a conscientização das populações locais.

Por fim, espera-se que os resultados obtidos neste estudo tenham utilidade para a construção de políticas de planejamento e gestão ambiental, na área de estudo. Além disso, espera-se que este trabalho estimule o uso de geotecnologias livres para o desenvolvimento de metodologias de zoneamento ambiental.

\section{Bibliografia}

AESA. Plano Estadual de Recursos Hídricos. João Pessoa: AESA, 2008.

AMORIM, R. R.; OLIVEIRA, R. C. Zoneamento ambiental, subsídio ao planejamento no uso e ocupação das terras da Costa do Descobrimento. Mercator, Fortaleza, v. 12, n. 29, p. 211-231, 2013.

ARAGÃO, A. K. O.; ALOUFA, M. A. I.; CAVALCANTE, J. S. I.; COSTA, D. F. S. Zoneamento ambiental como instrumento estratégico para a gestão municipal na Microrregião do Vale do Açu (RN). Geografia, Londrina, v. 23, n. 2. p. $95-112,2014$.

ARAÚJO, F. C. M. D. Os impactos ambientais da indústria têxtil em São Bento - PB. 2011. 57 f. Monografia (Licenciatura Plena em Geografia) - Faculdades Integradas de Patos, Patos, 2011.

BRASIL. Lei n 6.938, de 31 de agosto de 1981. Dispõe sobre a Política Nacional do Meio Ambiente, seus fins e mecanismos de formulação e aplicação, e dá outras providências. Diário Oficial [da] República Federativa do Brasil, Brasília, DF, 01 set. 1981. Disponível em: <http://www.planalto.gov.br/ccivil_03/leis/L6938.htm>. Acesso em: 29 nov. 2016.

CONGEDO, L. Semi-Automatic Classification Plugin for QGIS. Roma: Sapienza University of Rome, 2013. 25 p. 
COSTA, D. F. S.; GUEDES, J. C. F.; ROCHA, R. M. Estratégia de zoneamento ambiental aplicada à gestão das margens de reservatórios. Geosul, Florianópolis, v. 29, n. 58, p 145-159, 2014.

DIAS, R. L.; BACC, P. H.; OLIVEIRA, R. C. Santos. In: CUNHA, C. M. L.; OLIVEIRA, R. C. (Orgs.). Baixada Santista: uma contribuição à análise geoambiental. 1. ed. São Paulo: Editora Unesp Digital, 2015. p. 91-116.

DINIZ, M. T. M.; OLIVEIRA, G. P. Compartimentação e caracterização das unidades de paisagem do Seridó Potiguar. Brazilian Geographical Journal, Ituiutaba, v. 6, n. 1, p. 291-318, 2015.

DINIZ, M. T. M.; VASCONCELOS, F. P. Análise integrada da paisagem como suporte à gestão integrada da zona costeira: adaptação de metodologia da Unesco à costa semiárida brasileira. Terra Livre, São Paulo, v. 2, n. 35, p. 103-122, 2010.

EMBRAPA. Levantamento exploratório - Reconhecimento de solos do estado da Paraíba. Recife: EMBRAPA, 1972. $683 \mathrm{p}$.

EMBRAPA. Sistema Brasileiro de Classificação de Solos. 4. ed. Brasília, DF: EMBRAPA, 2014. 376 p.

GIGLIOTTI, M. S.; OLIVEIRA, R. C. Zoneamento geoambiental da região metropolitana da Baixada Santista. In:

CUNHA, C. M. L.; OLIVEIRA, R. C. (Orgs.). Baixada Santista: uma contribuição à análise geoambiental. 1. ed. São Paulo: Editora Unesp Digital, 2015. p. 35-60.

GUEDES, J. C. F.; MEDEIROS, A. D.; COSTA, D. F. S. Estratégia de Zoneamento Ambiental Aplicada a Caracterização Ambiental de Bacias Hidrográficas do Semiárido Brasileiro: Estudo de Caso na Microbacia do Rio Barra Nova - RN/PB. Revista de Geociências do Nordeste, v. 2, n. Especial, p. 1011-1024, 2016.

IBGE. Manual técnico de uso da terra. 3. ed. Rio de Janeiro: IBGE, 2013.

IBGE. Produção Agrícola Municipal 2015. SIDRA, Rio de Janeiro, 2015. Disponível em: < http://www2.sidra.ibge.gov.br/bda/tabela/protabl.asp?c=5457\&z=t\&o=4\&i=P>. Acesso em: 20 dez. 2016.

IBGE. Instituto Brasileiro de Geografia e Estatísticas. Síntese do município de São Bento - PB. @ Cidades, Rio de Janeiro, Dez. 2016. Disponível em: < http://www.cidades.ibge.gov.br/v3/cidades/municipio/2513901>. Acesso em: 12 dez. 2016.

MEER, F. D.; WERFF, H. M. A.; RUITENBEEK, F. J. A. Potential of ESA's Sentinel-2 for geological applications. Remote Sensing of Environment, v. 148, n. 1, p. 124-133, 2014.

MOLION, L. C. B.; BERNARDO, S. O. Uma revisão da dinâmica das chuvas no nordeste brasileiro. Revista Brasileira de Meteorologia, Rio de Janeiro, v. 17, n. 1, p. 1-10, 2002. 
NÍMER, E. Clima. In: IBGE. Geografia do Brasil: Região Nordeste. Rio de Janeiro: IBGE, 1977. p. 47-84.

OLIVEIRA, G. P.; DINIZ, M. T. M. Esboço de caracterização fisiográfica e compartimentação geoambiental do município de São Bento/PB. In: ENCONTRO ESTADUAL DE GEOGRAFIA DO RIO GRANDE DO NORTE, 21., 2014, Caicó. Anais... Natal: EDUFRN, 2015. p. 364-373.

SANTOS, E. J.; FERREIRA, C. A.; SILVA JR., J. M. F. Programa Levantamentos Geológicos Básicos do Brasil. Projeto Geologia e Recursos Minerais do Estado da Paraíba. Mapa Geológico do Estado da Paraíba. Escala: 1:500.000. Recife: CPRM/DNPM, 2002.

SOUZA, M. J. N. de. Bases Naturais e Esboço do Zoneamento Geoambiental do Estado do Ceará. In: LIMA, L. C., SOUZA, M. J. N., MORAIS, J. O. Compartimentação Territorial e Gestão Regional do Ceará. Fortaleza: Funece, 2000. p. 6-104.

SUDENE. Dados pluviométricos mensais do Nordeste. Recife: SUDENE, 1990. (Série Pluviometria 1 a 10).

SWAIN, P. H.; DAVIS, S. M. Remote sensing: the quantitative approach. New York: McGrawHill, 1978. 396 p. 